\title{
Hazard Ranking of Wastewater Sources in a Highly Polluted River in Northern Taiwan by Using Positive Matrix Factorization With Metal Elements
}

\section{Peiyuan Hsieh}

National Taiwan University https://orcid.org/0000-0002-7843-8374

Huan-Chun Lin

National Taiwan University

Gen-Shuh Wang

National Taiwan University

Yuan-Jeng Hsu

Environmental Protection Administration

Yi-Ju Chen

Environmental Protection Administration

Tzu-Hui Wang

Environmental Protection Administration

\section{Ren-De Wang}

Environmental Protection Administration

Chun-Yu Kuo

Environmental Protection Administration

\section{Di-Wen Wang}

Environmental Protection Administration

Ho-Tang Liao

National Taiwan University

Chang-Fu Wu ( $\nabla$ changfu@ntu.edu.tw)

National Taiwan University https://orcid.org/0000-0003-2244-1934

\section{Research Article}

Keywords: River water pollution, Industrial wastewater, Source profile, Source apportionment

Posted Date: February 10th, 2022

DOI: https://doi.org/10.21203/rs.3.rs-1236922/v1 
License: (c) (i) This work is licensed under a Creative Commons Attribution 4.0 International License. Read Full License 
1 Hazard ranking of wastewater sources in a highly polluted river in northern

3 Pei-Yuan Hsieh ${ }^{1}$, Huan-Chun Lin ${ }^{1}$, Gen-Shuh Wang ${ }^{1}$, Yuan-Jeng Hsu², Yi-Ju Chen², Tzu-Hui Wang ${ }^{2}$,

$5{ }^{1}$ Institute of Environmental and Occupational Health Sciences, National Taiwan University, Taipei, 6 Taiwan

$7 \quad{ }^{2}$ Environmental Analysis Laboratory, Environmental Protection Administration, Executive Yuan, 8 Taoyuan, Taiwan

$9 \quad *$ Correspondence: changfu@ntu.edu.tw 
11 Improving water quality is a critical issue worldwide. However, the general parameters (i.e.,

12 temperature, $\mathrm{pH}$, turbidity, total solids, fecal coliform, dissolved oxygen, biochemical oxygen demand,

13 phosphates, and nitrates) used in water quality index estimations are unable to identify pollution from

14 industrial wastewater. This study investigated pollution sources at a river pollution hotspot by using

15 the positive matrix factorization (PMF) model. A two-phase sampling collection along a highly

16 polluted river in northern Taiwan was designed. The sampling spots were distributed along the river in

17 Phase I to monitor the spatial variation of river pollutants. A pollution hotspot was determined based

18 on two indices, namely the summed concentrations of elements and a metal index (MI). In Phase II,

19 the river water samples were collected from the hotspot twice daily over 30 consecutive days to

20 monitor the temporal variation of river pollutants. Source profiles of metal elements were obtained

21 during the monitoring period. The Phase II samples were then factorized using the PMF model. Factor

22 profiles retrieved from the PMF model were further assigned to industrial categories through Pearson

23 correlation coefficients and hierarchical classification. The results indicated that the main pollution

24 source was bare printed circuit boards (BPCB), which contributed up to $92 \%$ of the copper in the

25 pollution hotspot. In terms of MI apportionment of 11 metals related to health effects, BPCB

26 contributed $91 \%$ of the MI in high pollution events. Overall, the MI apportionment provides linkages

27 between pollution level and human health. This is an evidence for policymakers that the regulation of

28 the effluents of BPCB is an effective means to controlling copper concentrations and thus improving 
29 water quality in the study area.

30 Keywords: River water pollution; Industrial wastewater; Source profile; Source apportionment

\section{1. Introduction}

32 On September 25, 2015, the 193 member states of the United Nations adopted the 2030 Agenda for

33 its 17 Sustainable Development Goals (SDGs) [1]. The agenda was expected to guide the actions of

34 international communities over the next 15 years (2016-2030). One of the 17 SDGs involves

35 improving water quality by reducing river water pollution. The causes of river water pollution include

36 industrial activity, domestic sewage, livestock wastewater, and agricultural wastewater.

37 The water quality index (WQI) is commonly used to evaluate general water quality [2-4]. Multiple

38 parameters are involved in the estimation of WQI scores, and weighted coefficients are assigned to

39 each parameter based on statistical surveys. The general parameters are temperature, $\mathrm{pH}$, turbidity,

40 total solids, fecal coliform, dissolved oxygen, biochemical oxygen demand, phosphates, and nitrates

$41[5,6]$. However, an index using these parameters generally cannot be used to measure pollution from

42 industrial wastewater.

43 River water influenced by discharge from an industrial district usually has a complex composition

44 including metal elements, water-soluble ions, and volatile organic compounds. Stable and non-

45 degradable metal elements could act as suitable tracers for monitoring pollution discharged by

46 industries [7, 8]. A metal index (MI) based on maximum allowable concentration (MAC) has been

47 introduced to evaluate the quality of water resources $[9,10]$. Usually, the MAC of an element is set by 
48 regulatory agencies to protect human health and ecological environment, which makes the MI a

49 valuable indicator.

50 To decrease the health hazards of polluted water and improve water quality, identifying pollution

51 sources is critical. Various statistical techniques have been applied for source apportionment. Principle

52 component analysis (PCA) has been widely used in the source apportionment of water pollution [11-

53 15]. PCA yields linear combinations of original features and can transform large datasets into a set of

54 factors with reduced dimensions. However, PCA can only provide qualitative information, and it is

55 susceptible to outliers. Furthermore, the results of PCA does not have physical meaning because the

56 values of factors decomposed using PCA can be negative. Positive matrix factorization (PMF) is

57 recognized as an effective scientific tool and as an improved factor analysis tool for source

58 apportionment [16]. Many studies have successfully applied PMF to the source apportionment of

59 ambient particulate matter $[17,18]$. In recent years, PMF has also been used to investigate pollution

60 sources in aqueous environments [e.g., 19, 20-23]. PMF has the following advantages: (1) it includes

61 the integration of non-negative constraints; (2) uncertainties in the data are introduced into the model;

62 (3) it does not need to be orthogonal, which makes the formed factors close to real profile of pollution

63 sources; (4) it quantifies source contributions; and (5) the factors are not excessively influenced by

64 outliers [24-26]. However, in most of these studies, source apportionment was estimated using spatial

65 samplings, which neglected temporal variation in the source contributions. Furthermore, the number

66 of metal species was limited and may be insufficient to distinguish complex industrial sources. 
67 The objective of this study was to use metal species with a receptor model to estimate potential

68 source profiles and their contributions in a river pollution hotspot. The Ta-Liao-Keng River was

69 selected as an example to demonstrate the feasibility of the approach. To the best of our knowledge,

70 this is the first study adopting sequential time series data of river water samples for PMF modeling

71 with factor profiles identified by comparison with profiles obtained from industrial effluents. Potential

72 sources of MI and their contributions were apportioned to clarify the relationship between pollution

73 levels and human health.

\section{2. Material and Methods}

\section{2.1. Study Area and River Water Sample Collection}

76 The Ta-Liao-Keng River is a tributary of the Dahan River, which is a major river in Taiwan (Fig. 1).

77 The length of the Ta-Liao-Keng River is $12.3 \mathrm{~km}$, and its catchment area is approximately $29.4 \mathrm{~km}^{2}$.

78 The river has four branches and flows eastward from Taoyuan City to New Taipei City (A fishbone

79 diagram is provided as Fig. S1). The main industrial area is located at a downstream section of the

80 river and is especially concentrated on Tandigou, a tributary ( $\mathrm{S} 4$ in Fig. 1). According to a report

81 published by the local government in 2017, the Ta-Liao-Keng River was the main contributor of copper

$82(\mathrm{Cu})$ to the Dahan River. Thus, further investigation of the source pollution, especially for $\mathrm{Cu}$, in the

83 Ta-Liao-Keng River is imperative.

84 For this study, a sampling scheme with two phases was designed. In the first phase (Phase I, end of

85 April 2019), four sampling sites along the Ta-Liao-Keng River were selected to locate a hotspot for 
86 further investigation. The river water quality was monitored from downstream to upstream. Four

87 additional sampling sites at four branches served as background sites. A total of eight river water

88 samples were collected during this phase.

89 Two pollution indices, the sum of elemental concentrations and MI, were applied to investigate the

90 pollution hotspot. The MI was defined as

$$
\mathrm{MI}=\sum_{i} \frac{C_{i}}{\left(M A C_{i}\right)}
$$

91 where $C_{i}$ is the concentration of one of 11 controlled elements, i.e., silver (Ag), arsenic (As), cadmium

$92(\mathrm{Cd}), \mathrm{Cu}$, hexavalent chromium $\left(\mathrm{Cr}^{6+}\right)$, mercury $(\mathrm{Hg})$, manganese $(\mathrm{Mn})$, nickel $(\mathrm{Ni})$, lead $(\mathrm{Pb})$,

93 selenium (Se), and zinc $(\mathrm{Zn})$. Table 1 presents the MAC values of these 11 elements, which are

94 enforced by Taiwan Environmental Protection Administration (TEPA), for surface water. Because

95 trivalent chromium and $\mathrm{Cr}^{6+}$ can convert back and forth, a measurement of total chromium can avoid

96 missing one of these. Instead of using $\mathrm{Cr}^{6+}$, total chromium was measured and used to estimate the MI.

97 Pollution is a cause for concern when the MI is greater than one.

98 In the second phase (Phase II, July 2019), samples were collected twice daily over 30 consecutive

99 days $(\mathrm{N}=60)$ at the hotspot identified in Phase I. The collected samples were used to evaluate temporal

100 variation in river water pollution and for PMF modeling.

\subsection{Sampling of Industrial Wastewater}

To investigate potential pollution sources and assign them to industrial categories, representative 
104 collected as source profiles. Furthermore, because the river could be contaminated by untreated

105 wastewaters which were discharged by factories unintentionally, three manufacturing units were

106 selected for sampling based on previous violations. Most industrial wastewater samples were collected

107 twice during the sampling time to reduce uncertainty in the source profiles (Table S1). Overall, samples

108 were collected for six industrial categories: chemical materials and products (CMP), bare printed

109 circuit boards (BPCB), electroplating products (EP), food manufacturing (FM), finishing of textiles

110 (FT), and metal surface treatment (MST). To further investigate the association between human

111 activities and the river pollution, domestic sewage (DS) was collected as a potential source. The

112 wastewater samples were collected and preserved in accordance with the standard method [27].

\section{2.3. Chemical Analysis}

114 To quantify metal elements and trace elements in river water and wastewater samples, inductively

115 coupled plasma-mass spectrometry was used according to the standard method [28]. A total of 52

116 elements were analyzed and the method detection limit (MDL) of these elements ranged from $0.03 \mu \mathrm{g}$

$117 \mathrm{~L}^{-1}$ to $1.67 \mu \mathrm{g} \mathrm{L}^{-1}$ (Table S2).

118

\subsection{Source Apportionment}

The PMF 5.0 software released by U.S. Environmental Protection Agency was used for source

apportionment in the second phase [29]. In PMF modeling, the mass balance equation is expressed as

$$
X_{i j}=\sum_{k=1}^{p} g_{i k} f_{k j}+e_{i j}
$$

121 where $X_{i j}$ is the $j$ th species concentration measured in the $i$ th sample, $g_{i k}$ is the contribution of the 
$122 k$ th source pollution in the $i$ th sample, $f_{k j}$ is the source profile defined by the $j$ th species concentration

123 in the contribution of the $k$ th source pollution, and $e_{i j}$ is the residual.

124 The uncertainty of measurements in PMF is calculated using

$$
u_{i j}=\sqrt{\left(0.5 \times M D L_{i j}\right)^{2}+\left(0.1 \times X_{i j}\right)^{2}}
$$

125 when the measured concentration is higher than the MDL [29]. When the measured concentration is

126 less than the MDL, the concentration is replaced with half the MDL, and the uncertainty is estimated

127 as follows:

$$
u_{i j}=\frac{5}{6} \times M D L_{i j}
$$

128 In PMF, the objective function is defined using

$$
\mathrm{Q}(\mathrm{E})=\sum_{i=1}^{n} \sum_{j=1}^{m}\left(\frac{e_{i j}}{u_{i j}}\right)^{2}
$$

129 where $n$ is the number of samples and $m$ is the number of species. The optimal values of contributions

$130\left(g_{i k}\right)$ and sources profiles $\left(f_{k j}\right)$ can then be retrieved by minimizing Q(E).

131 To determine the number of factors, PMF was run sequentially using a varied number of factors

132 from 3 to 8 . The scaled residual $\left(r_{i j}\right)$ of each run is used to calculate the maximum individual column 133 mean (IM),

$$
\mathrm{IM}=\max _{j=1 \ldots m}\left(\frac{1}{n} \sum_{i=1}^{n} r_{i j}\right)
$$

134 and the maximum individual column standard deviation (IS), 


$$
\mathrm{IS}=\max _{j=1 \ldots m}\left(\sqrt{\frac{1}{n-1} \sum_{i=1}^{n}\left(r_{i j}-\bar{r}_{l}\right)^{2}}\right)
$$

135 The appropriate number of factors is that for which the derivatives of IM and IS seem to level off [30].

136 In PMF modeling, bootstrapping is performed to estimate the stability of the solution. The

137 reproducibility of bootstrapping on each run (three to eight factors) is used to determine the number

138 of factors, as well. In this study, 100 was chosen for the number of bootstrap runs.

\section{3. Results and Discussion}

\section{3.1. Spatial and Temporal Variations in River Water Measurements}

141 The sum of elemental concentrations was low upstream and gradually increased along the river in

142 Phase I (Table S3, Sites S8, S5, S3, and S1). The two species with the highest concentrations were

143 aluminum $(\mathrm{Al})$ and iron $(\mathrm{Fe})$; the sum of $\mathrm{Al}$ and $\mathrm{Fe}$ at $\mathrm{S} 6$ was $86 \%$ of the elemental concentrations. $\mathrm{Al}$

144 and $\mathrm{Fe}$ are the most abundant metals in the Earth's crust. To focus on industrial pollutants, $\mathrm{Al}$ and $\mathrm{Fe}$

145 were eliminated from the following estimations. The highest elemental concentration was observed at

146 Tandigou (S4), a tributary of the Ta-Liao-Keng River. The concentration at S4 was almost six times

147 greater than that of the background water (S8). The second highest value was observed in the other

148 tributary, S2. The high concentrations in tributaries instead of in the main stream was probably due to

149 inputs from domestic wastewater and industrial effluents in the downstream area. The MI at S4 was

150 up to 42.8, 17 times higher than that at S8, which indicated high levels of pollution at S4. Based on the

151 spatial analysis of the metal elements in Phase I, S4 was chosen as the pollution hotspot. 
In Phase II, the pollution hotspot was monitored twice daily over 30 consecutive days beginning on

153 July 1, 2019. Summary statistics for the measured elemental concentrations are provided in Table S2.

154 The three elements with the highest mean concentrations (exclude $\mathrm{Al}$ and $\mathrm{Fe}$ ) were $\mathrm{Cu}\left(1245 \mu \mathrm{g} \mathrm{L}^{-1}\right)$,

$155 \mathrm{Zn}\left(558 \mu \mathrm{g} \mathrm{L}^{-1}\right)$, and $\mathrm{Ni}\left(313 \mu \mathrm{g} \mathrm{L}^{-1}\right)$. When applying the PMF model, data pretreatment is crucial.

156 Species must be removed if more than $70 \%$ of the data points are below the detection limit. In this

157 study, the following 13 species were excluded: dysprosium, erbium, europium, hafnium, holmium,

158 iridium, platinum, ruthenium, samarium, tellurium, thulium, ytterbium, and zirconium. Most of the

159 excluded species are rare earth elements and precious metals. Furthermore, data quality is evaluated

160 by signal-to-noise ratios in PMF modeling and inadequate species can be weighted down or eliminated

161 during the optimization. We eliminated six elements with poor fit, namely gold, boron, cobalt,

162 molybdenum, antimony, and tantalum. Finally, 31 of the 50 elements were included in the PMF model.

163 The highest total elemental concentration at S4 was observed on July 1 when the concentration was

164 up to $13465 \mu \mathrm{g} \mathrm{L} \mathrm{L}^{-1}$ (Fig. 2). The second highest total elemental concentration, $9100 \mu \mathrm{g} \mathrm{L} \mathrm{L}^{-1}$, was

165 observed on July 15. In terms of the MI, the largest value, 258, was also observed on July 1 (Fig. 3).

166 The second largest MI value, 170, was observed on July 4. A discrepancy was discovered when

167 defining the high pollution events using two indices. This is discussed in the following sections.

\subsection{Characteristics of the Metal Elements in Industrial Wastewater}

Most industrial wastewater was collected twice, and the samples for each factory were averaged to 
171 (with "m" in front of the category) discharges are illustrated in Fig. 4. CMP was represented by a

172 battery factory, which emitted a high concentration of $\mathrm{Pb}$. The profiles for BPCB were dominated by

$173 \mathrm{Cu}$, which comprised up to $82 \%$ of total elemental concentrations. The profiles of the EP were

174 dominated by $\mathrm{Ni}$, with proportions of up to $88 \%$. FM was represented by a factory making frozen food,

175 where discharge had high concentrations of strontium ( $\mathrm{Sr}$ ) and rubidium. The profile of FT was

176 dominated by Sr and Mn. The MST was represented by a manufacturer of aluminum-related products,

177 and Mn and Ni were dominant in its profile. The profile of DS was collected at an apartment complex

178 and was dominated by Mn and Sr. All compositions followed the effluent standards established by the

179 TEPA.

180 3.3. Source Apportionment

181 IM and IS analyses indicated that possible solutions were around six factors (Fig. S2). To identify

182 the optimal solution, bootstrap analysis was introduced (Table S4). This revealed that five factors

183 provided the most stable solution with the mapping rate $>80 \%$ for each factor. The averaged source

184 contributions of total elemental concentrations (the sum of 31 elements) and of $\mathrm{Cu}$ are depicted in Fig.

185 5. Factor 4 was the greatest contributor (36\%) to total elemental concentrations, followed by Factor 1

$186(19 \%)$ and Factor 5 (16\%). For $\mathrm{Cu}$, Factors 4 and 1 offered even larger contributions (64\% and 28\%, 187 respectively).

188 The measured total elemental concentrations and the contributions of Factors 1, 4, and 5 over time 189 are presented in Fig. 2. The contribution of Factor 4 closely matched certain high pollution events. On 
190 July 4, Factor 4 contributed $86 \%$ of total elemental concentrations and decreased in the afternoon.

191 Factor 1 was the main contributor (76\%) of the highest pollution event on July 1 even though it was

192 not a persistent pollution source. By contrast, Factor 5 was a stable, persistent source of pollution, but

193 its contribution was relatively small. Concentrations of $\mathrm{Cu}$ were greater than $3000 \mu \mathrm{g} \mathrm{L}^{-1}$ in many high

194 pollution events (Fig. S3), and the ratio of $\mathrm{Cu}$ to total elemental concentration was $>50 \%$. Factor 1

195 was the significant contributor of $\mathrm{Cu}$ on July 1. Factor 4 was the main source of $\mathrm{Cu}$ in high pollution

196 events, except for the highest one.

197 For Factor 1, Cu comprised 65\% of the normalized profile (Fig. S4). Cu was also dominant in

198 Factor 4 and represented up to $78 \%$ of total elemental concentrations. Instead of $\mathrm{Cu}, \mathrm{Mn}$ and $\mathrm{Sr}$ were

199 significant in Factor 5. To identify the industrial categories of the factors we focused on, Pearson

200 correlations and hierarchical classifications were used. Table 2 lists the correlations of Factors 1, 4, 5,

201 with all source profiles collected in this study. Factors 1 and 4 had strong correlations $(\mathrm{r} \geq 0.96)$ with

202 BPCB1, BPCB2, and their manufacturing unit discharges. The correlation between Factor 1 and Factor

2034 was as high as 0.99 . This indicated that Factors 1 and 4 were in the same industrial category. Factor

2045 was highly correlated with DS $(r=0.95)$. Fig. 6 depicts a cluster dendrogram of the hierarchical

205 classification of the factors and source profiles. Factor 1 was similar to BPCB1 and its manufacturing

206 unit discharge, and Factor 4 was similar to BPCB2 and its manufacturing unit discharge. Among all

207 source profiles and factors, BPCB1 and BPCB2 were prominent in the hierarchical clustering.

208 Moreover, Factor 5 was closely related to DS. BPCB1 and BPCB2 are Cu-dominated, and the profile 
209 of DS is dominated by Mn and Sr. Overall, the profile matching based on the two methods was

210 consistent, and the markers for the estimated factors corresponded to those in the measured profiles.

211 Factors 1 and 4 were classified as BPCB1 and BPCB2, respectively, and Factor 5 was classified as DS.

212 3.4. MI Apportionment

213 These analyses in the previous section have focused on source apportionments for mass

214 concentrations. From the perspective of protecting human and ecological health, further quantifying

215 the contributions of sources to MI, which considered both the concentrations and MAC of the main

216 toxic elements, is needed. The source-specific MI of the $p$ th source $\left(M I_{p}\right)$ was calculated using

$$
M I_{P}=\sum x^{*}{ }_{j p} M I_{j}
$$

217 where $x_{j p}^{*}$ is the mean concentration of species $j$ in source $p$, based on the model results, and $M I_{j}$ is

218 the unit MI for species $j$.

219 The averaged MI was 53.9, with Cu contributing up to 77\%. The other highly polluting species was

220 Mn (10\%), followed by Ni (6\%). Fig. 5(c) presents the MI apportionment results. Factor 4, which was

221 classified as BPCB2, was the main MI contributor (53\%) at S4. The second highest contributor (24\%)

222 was Factor 1, which was classified as BPCB1. The sum of MI contributions from BPCB1 and BPCB2

223 was up to $77 \%$, indicating that BPCB was the industrial category with the greatest health risk at S4.

224 Fig. 3 presents the time series of the measured MI scores and those of the two largest contributors.

225 To compare the source contribution during pollution events and nonevents, high pollution events

226 (HPEs) were defined as those with MI > 99.3 (mean MI plus one standard deviation), and other events 
227 classified as general conditions (GCs). Nine HPEs were identified. The averaged MI of the HPEs was

228 143, whereas the averaged MI of the GCs was 38. The health risk of the HPEs was approximately 3.8

229 times greater than that of the GCs. For Events 2, 4, 6, 7, 8, and 9, BPCB2 was the main MI contributor;

230 for Event 1, BPCB1 was the main contributor. By contrast, the pollutants of Event 5 were almost

231 equally contributed by both BPCB1 and BPCB2. For Event 3, no obvious contributor was identified,

232 which was also evidenced by the PMF model not fitting this event well. Overall, BPCB1 and BPCB2

233 were the main MI contributors to HPEs; the sum of their MI contributions was up to 91\% (Fig. 7).

234 During GCs, BPCB1 and BPCB2 were also the largest health risk contributors, and the sum of their

235 contributions was $79 \%$. DS contributed the second greatest health risk, with a $15 \%$ contribution.

236 Although DS was not a dominant source pollution in HPEs, it was a stable source pollution that

237 contributed $9 \%$ of the averaged MI.

\section{3.5. Limitations}

239 In this study, the MI was considerably higher than the reference value because of stringent MAC of

$240 \mathrm{Cu}$ in Taiwan. The guideline for drinking water quality published by the World Health Organization

241 [31] is $2000 \mu \mathrm{g} \mathrm{L}^{-1}$ for $\mathrm{Cu}$, but the MAC of $\mathrm{Cu}$ is $30 \mu \mathrm{g} \mathrm{L}^{-1}$ in Taiwan. This makes estimates of the MI

242 higher if $\mathrm{Cu}$ is the main pollutant. Another limitation is that the result estimated by the PMF model

243 provided only information on source contributions by industrial categories and not the exact source

244 locations. Nevertheless, this modeling approach is valuable in narrowing down pollution sources to 245 specific industrial categories. 


\section{Conclusions}

247 This study investigated the source contributions at a river pollution hotspot by using PMF. This was

248 the first study to apply sequential time series data of metal species in PMF to apportion sources and

249 their contributions by industrial category. The results revealed that the main source was BPCB, and

250 the sum of BPCB1 and BPCB2 contributions was up to 55\% of the total elemental concentrations and

$25192 \%$ of copper in the study area. Because $\mathrm{Cu}$ element was the main pollutant in BPCB which was the

252 main contributor, this leads to severe copper pollution in Tandigou. BPCB contributed $75 \%$ of total

253 elemental concentrations in MI. For both elemental concentrations and the MI, which is related to

254 human and ecological health, BPCB was the main contributor. In further investigation of the source

255 pollution in HPEs, the MI contribution from BPCB was up to $91 \%$. The results indicated that BPCB

256 contributed toxic pollutants and that led to a high percentage of MI contribution.

257 In this study, we demonstrated the feasibility of using metal species with a receptor model to identify

258 source pollution. The model results might provide useful information to policymakers for the effective

259 management of river environments. For further investigation of river pollution, establishing a

260 comprehensive source profile database is highly recommended for source identification.

\section{Declarations}

\section{Availability of data and materials}

263 Restrictions apply to the availability of these data, which were used under license for this study. The

264 data are available from the corresponding author with the permission of Environmental Analysis 
265 Laboratory, Environmental Protection Administration, Taiwan.

\section{Competing interests}

267 The authors declare that they have no competing interests.

\section{Funding}

269 This work was funded by the National Institute of Environmental Analysis, Environmental Protection

270 Administration of Taiwan (EPA154109001), and the Featured Areas Research Center Program within

271 the framework of the Higher Education Sprout Project by the Ministry of Education of Taiwan (NTU-

272 109L9003).

\section{Author's contributions}

274 Peo-Yuan Hsieh: Conceptualization, Methodology, Software, Formal Analysis, Investigation, Writing

275 - original draft, Visualization. Huan-Chun Lin: Investigation, Writing - review \& editing. Gen-Shuh

276 Wang: Conceptualization, Supervision, Project administration. Yuan-Jeng Hsu: Investigation, Data

277 curation, Resources, Supervision, Project administration. Yi-Ju Chen: Resources, Data curation. Tzu-

278 Hui Wang: Resources, Data curation. Ren-De Wang: Resources, Data curation. Chun-Yu Kuo:

279 Resources, Data curation. Di-Wen Wang: Resources, Data curation. Ho-Tang Liao: Validation,

280 Writing - review \& editing. Chang-Fu Wu: Conceptualization, Supervision, Project administration,

281 Writing - review \& editing.

282 Acknowledgments

283 We thank our co-workers from the National Institute of Environmental Analysis, Environmental 
284 Protection Administration of Taiwan who greatly assisted and executed this project. We would also

285 like to show our gratitude to the samplers and analysts for their hard work.

\section{References}

287 1. UN-DESA. The Sustainable Development Goals Report 2017. United Nations Department of $288 \quad$ Economic and Social Affairs, New York, NY.; 2017.

289 2. Ott W. Water Quality Indices: a Survey of Indices Used in the United States. U.S. 290 Environmental Protection Agency, Washington, D.C.; 1978.

291 3. Kumar D, Alappat BJ. NSF-water quality index: does it represent the experts' opinion? Practice Periodical of Hazardous, Toxic, and Radioactive Waste Management 2009;13(1):75-9.

293 4. Horton RK. An index number system for rating water quality. J Water Pollut Control Fed. $1965 ; 37(3): 300-6$

295 5. Brown RM, McClelland NI, Deininger RA, Tozer RG. A water quality index- do we dare. Water 296 and Sewage Works 1970;117(10):339-43.

297 6. Lumb A, Sharma T, Bibeault J-F. A review of genesis and evolution of water quality index 298 (WQI) and some future directions. Water Qual Expo Health 2011;3(1):11-24.

$2997 . \quad$ Abdo M, El-Nasharty S. Physico-chemical evaluations and trace metals distribution in water300 surficial sediment of Ismailia Canal, Egypt. Nature and Science 2010;8(5):198-206.

3018 . Fishar M, Ali M. Accumulation of trace metals in some benthic invertebrate and fish species revelant to their concentration in water and sediment of Lake Qarun, Egypt. Egypt J Aquat Res. 
2005;31(1):289-301.

304 9. Goher ME, Hassan AM, Abdel-Moniem IA, Fahmy AH, El-sayed SM. Evaluation of surface water quality and heavy metal indices of Ismailia Canal, Nile River, Egypt. Egypt J Aquat Res. 2014;40(3):225-33.

10. Tamasi G, Cini R. Heavy metals in drinking waters from Mount Amiata (Tuscany, Italy). Possible risks from arsenic for public health in the Province of Siena. Sci. Total Environ. $2004 ; 327(1-3): 41-51$.

12. Kowalkowski T, Zbytniewski R, Szpejna J, Buszewski B. Application of chemometrics in river water classification. Water Res. 2006;40(4):744-52.

13. Palma P, Alvarenga P, Palma VL, Fernandes RM, Soares AM, Barbosa IR. Assessment of anthropogenic sources of water pollution using multivariate statistical techniques: a case study of the Alqueva's reservoir, Portugal. Environ. Monit. Assess. 2010;165(1-4):539-52.

14. Huang J, Ho M, Du P. Assessment of temporal and spatial variation of coastal water quality and source identification along Macau peninsula. Stoch. Environ. Res. Risk Assess. 
hydrocarbons in surface waters and riverine sediments of the Hooghly and Brahmaputra Rivers in the Eastern and Northeastern India. Sci. Total Environ. 2018;636:751-60.

324 16. Paatero P, Tapper U. Positive matrix factorization: A non-negative factor model with optimal utilization of error estimates of data values. Environmetrics 1994;5(2):111-26.

17. Belis C, Karagulian F, Larsen BR, Hopke P. Critical review and meta-analysis of ambient particulate matter source apportionment using receptor models in Europe. Atmos. Environ. Manag Assoc. 2016;66(3):237-59.

19. Soonthornnonda P, Christensen ER. Source apportionment of pollutants and flows of combined

18. Hopke PK. Review of receptor modeling methods for source apportionment. J Air Waste 2013;69:94-108. Sci. 2019;9(3):63. sewer wastewater. Water Res. 2008;42(8-9):1989-98.

20. Li H, Hopke PK, Liu X, Du X, Li F. Application of positive matrix factorization to source apportionment of surface water quality of the Daliao River basin, Northeast China. Environ. Monit. Assess. 2015;187(3):80.

21. Jiang J, Khan AU, Shi B, Tang S, Khan J. Application of positive matrix factorization to identify potential sources of water quality deterioration of Huaihe River, China. Appl. Water and surface water quality characterization through positive matrix factorization combined with 
GIS approach. Water Res. 2019;159:122-34.

342 23. Vu CT, Lin C, Shern C-C, Yeh G, Tran HT. Contamination, ecological risk and source Indic. 2017;82:32-42.

345 24. Bzdusek PA, Christensen ER. Comparison of a new variant of PMF with other receptor 2006;17(4):387-403.

348 25. Bzdusek PA, Lu J, Christensen ER. PCB congeners and dechlorination in sediments of 2006;40(1):120-9.

contributions at the measurement time scale. Atmospheric Chem. Phys. 2009;9(2):497-513.

Administration, Executive Yuan, R.O.C. (Taiwan); 2019.

28. TEPA. Method for the Determination of Metals and Trace Elements in Water by Inductively Coupled Plasma Mass Spectrometry (NIEA W313). Environmental Protection Administration, Executive Yuan, R.O.C. (Taiwan); 2019.

29. Norris G, Duvall R, Brown S, Bai S. Positive matrix factorization (PMF) 5.0-fundamentals and 
user guide. US Environmental Protection Agency, Washington DC; 2014.

361 30. Lee E, Chan CK, Paatero P. Application of positive matrix factorization in source apportionment of particulate pollutants in Hong Kong. Atmos. Environ. 1999;33(19):3201-12.

363 31. WHO. Guidelines for Drinking-Water Quality, 4th edition, incorporating the 1st addendum. Geneva, Switzerland: World Health Organization; 2017:631. 
366 Table 1 Water quality standards of TEPA for heavy metal content in surface water.

\begin{tabular}{lllllllllllll}
\hline Element & $\mathrm{Ag}$ & $\mathrm{As}$ & $\mathrm{Cd}$ & $\mathrm{Cr}^{6+}$ & $\mathrm{Cu}$ & $\mathrm{Hg}$ & $\mathrm{Mn}$ & $\mathrm{Ni}$ & $\mathrm{Pb}$ & $\mathrm{Se}$ & $\mathrm{Zn}$ \\
\hline $\mathrm{MAC}^{*}$ & & & & & & & & & & & \\
$\left(\mu \mathrm{g} \mathrm{L}^{-1}\right)$ & 50 & 50 & 5 & 50 & 30 & 1 & 50 & 100 & 10 & 10 & 500 \\
\hline
\end{tabular}

$367 \quad$ MAC $=$ maximum allowable concentration. 
368 Table 2 Correlations of Factors 1, 4, 5, with all source profiles.

\begin{tabular}{l|ccc}
\hline Source Pollution & Factor 1 & Factor 4 & Factor 5 \\
\hline CMP $^{\mathrm{a}}$ & -0.04 & -0.02 & 0.68 \\
BPCP1 & 0.98 & 0.98 & 0.24 \\
EP1 & 0.04 & 0.06 & 0.51 \\
BPCP2 & 0.96 & 0.98 & 0.21 \\
FM & 0.01 & 0.03 & 0.63 \\
FT & 0.03 & 0.05 & 0.72 \\
MST & 0.03 & 0.06 & 0.63 \\
EP2 & 0.49 & 0.49 & 0.14 \\
DS & 0.03 & 0.05 & 0.95 \\
BPCP1m & 0.98 & 0.98 & 0.16 \\
EP1m & 0.01 & 0.02 & 0.16 \\
BPCP2m & 0.98 & 0.98 & 0.13 \\
\hline
\end{tabular}

$369{ }^{\mathrm{a}} \mathrm{CMP}=$ chemical materials and products; $\mathrm{BPCB}=$ bare printed circuit boards; $\mathrm{EP}=$ electroplating

370 products; $\mathrm{FM}=$ food manufacturing; $\mathrm{FT}=$ finishing of textiles; $\mathrm{MST}=$ metal surface treatment; DS = 371 domestic sewage. Three manufacturing unit collected from BPCP1, EP1 and BPCP2 are with "m" in 372 front of the category.

$373{ }^{\mathrm{b}}$ The category with m means the manufacturing unit. 


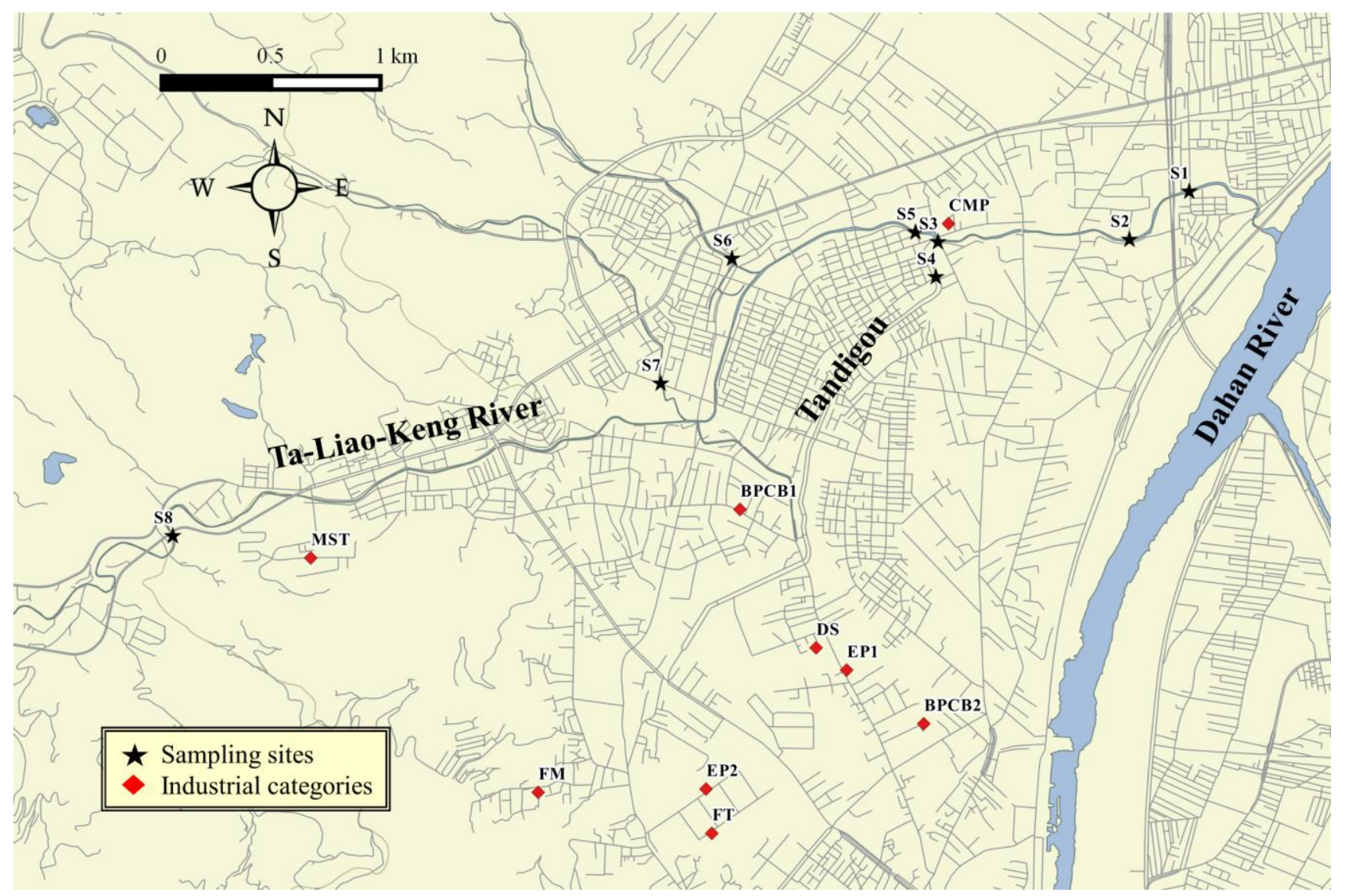

375 Fig. 1. Locations of the sampling sites in the Ta-Liao-Keng River. 
observed values $\quad$ …... Factor $1 \quad$ - 1 - Factor $4 \longrightarrow$ Factor 5

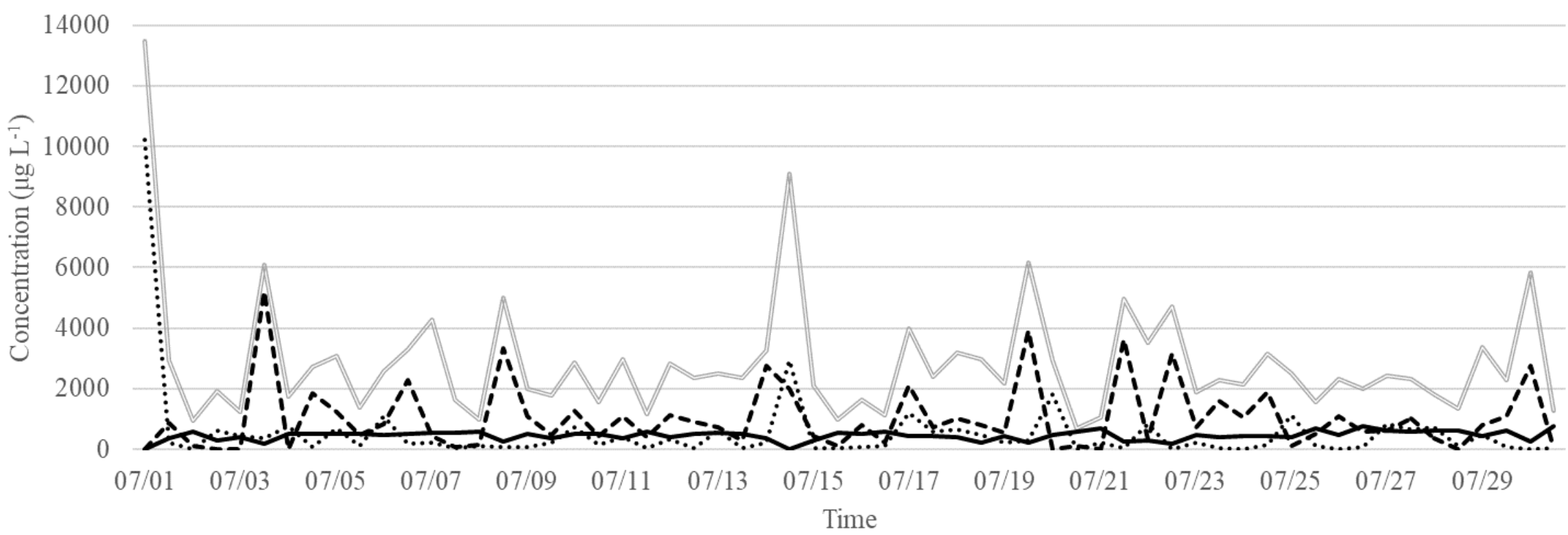

Fig. 2. Measured total elemental concentrations and the contributions of Factors 1, 4, and 5 over time. 


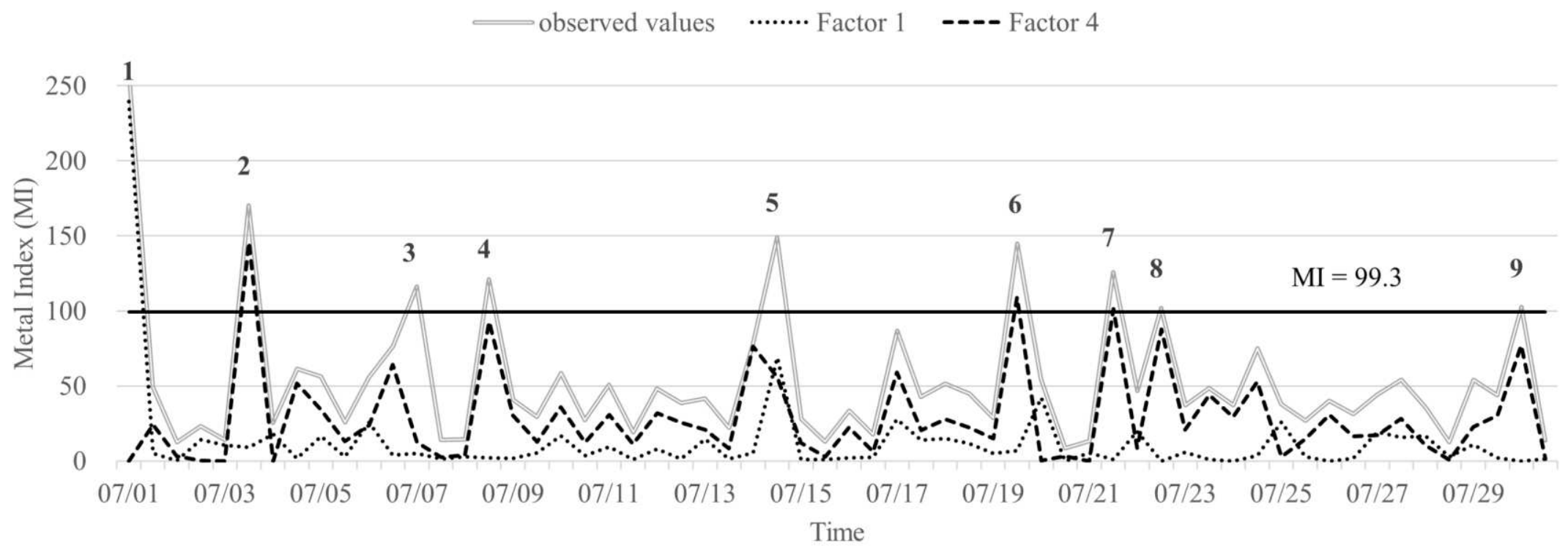

Fig. 3. Measured MI and contributions of Factors 1 and 4 estimated using PMF. 


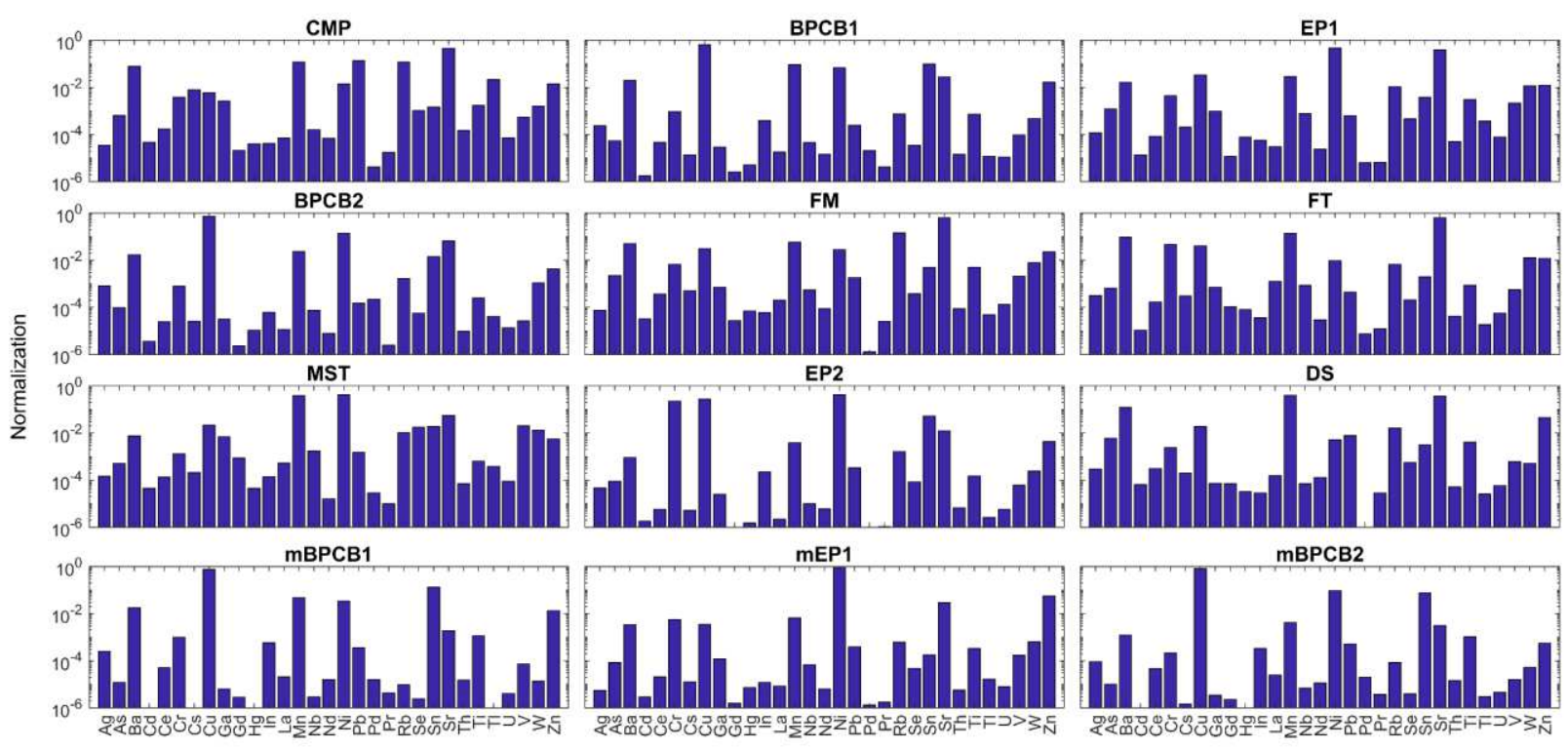

381 Fig. 4. Composite profiles of industrial effluents and manufacturing unit discharges. 
(a)

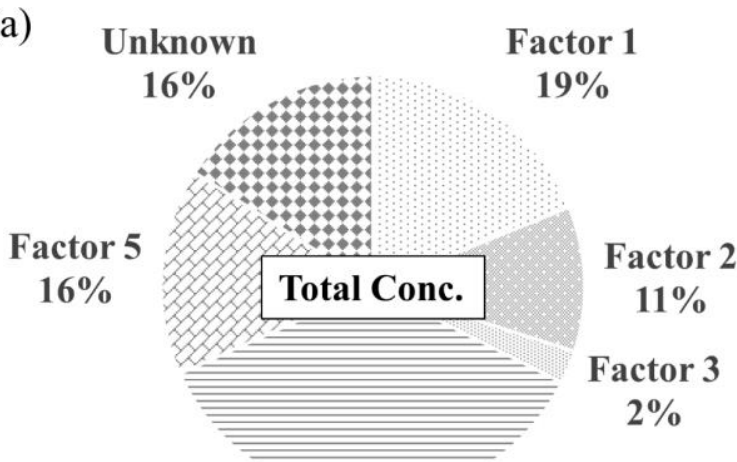

Factor 4 $36 \%$ (b) Unknown

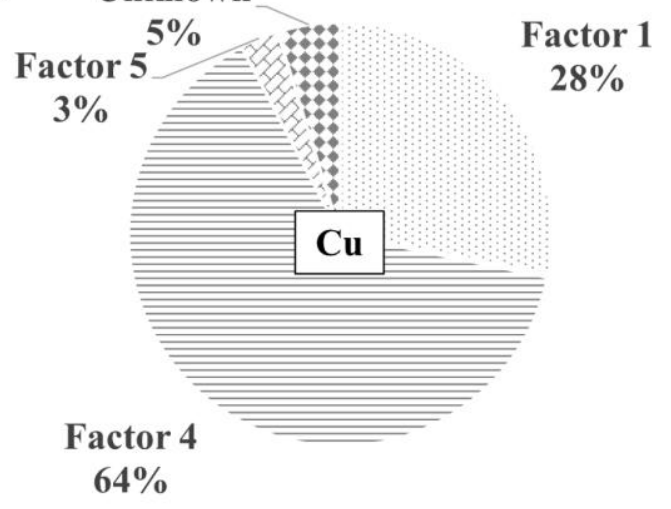

(c)

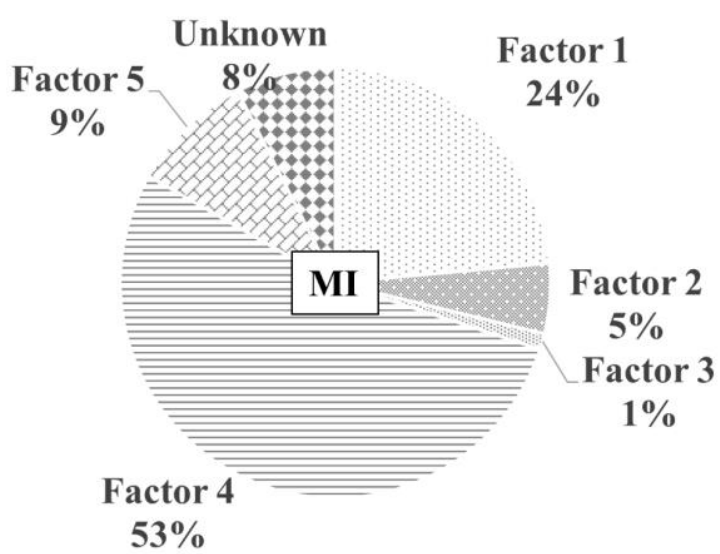

383 Fig. 5. Source contributions of five factors to (a) total elemental concentrations, (b) $\mathrm{Cu}$, and (c) MI. 


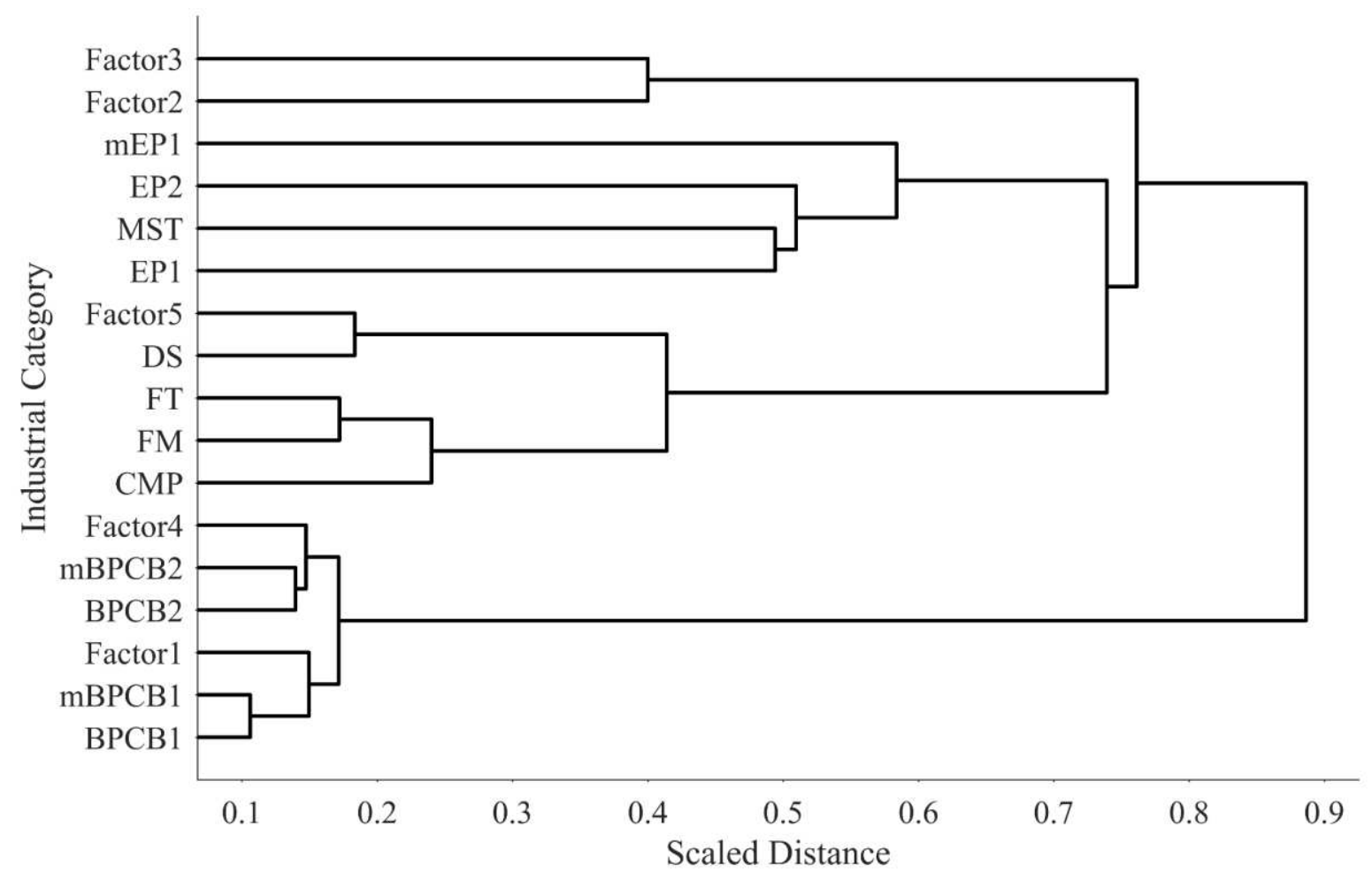

385 Fig. 6. Cluster dendrogram of hierarchical classification. 
$\mathbb{N}$ HPEs $\square$ GCs

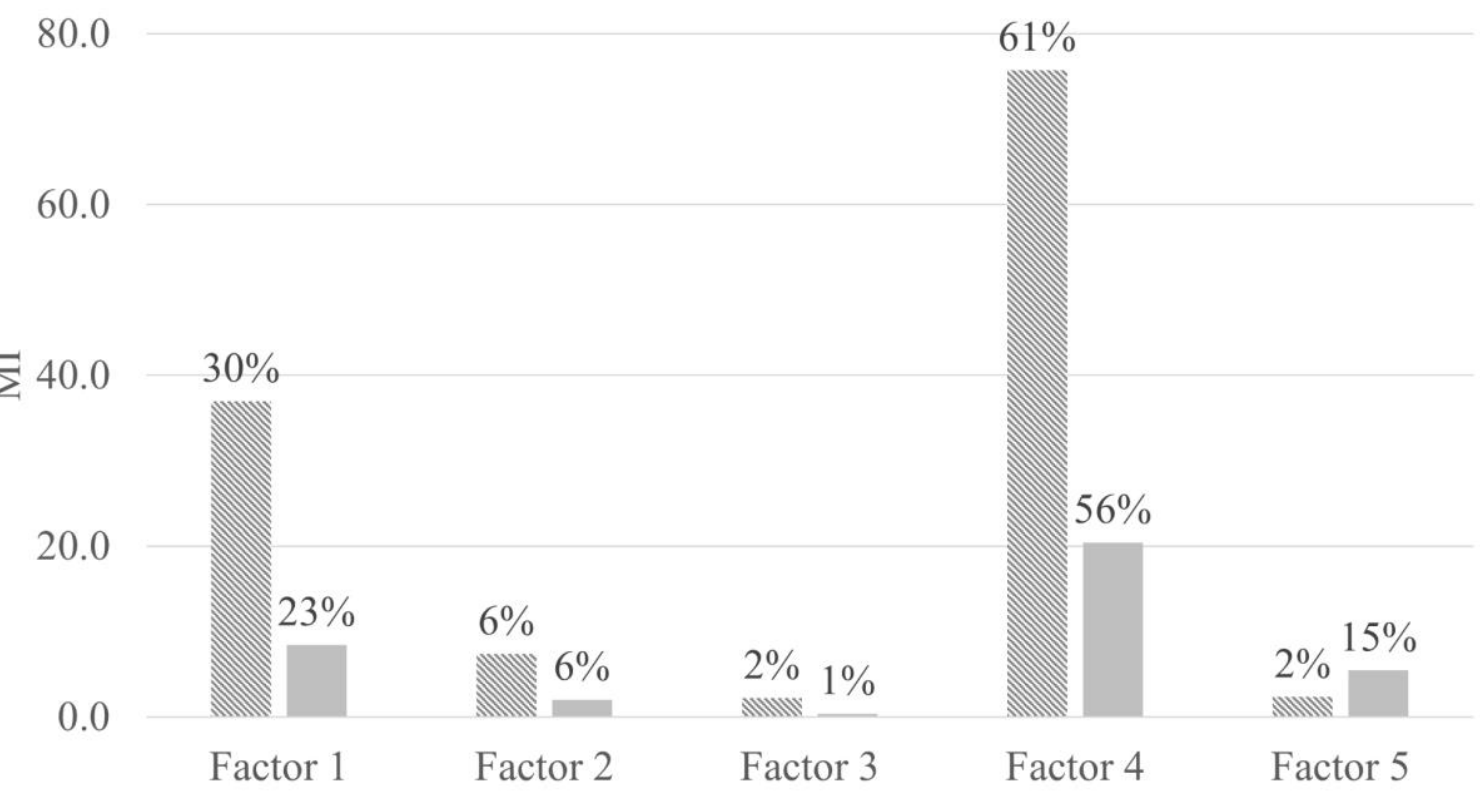

386

387 Fig. 7. MI apportionment in high pollution events (HPEs) and in general conditions (GCs). 


\section{Supplementary Files}

This is a list of supplementary files associated with this preprint. Click to download.

- supplmPMFtaliaokeng.docx 